\title{
PERSEPSI PASIEN TERHADAP PELAYANAN KEPERAWATAN: STUDI FENOMENOLOGI
}

\author{
Muhidin',2*, Junaiti Sahar ${ }^{3}$, Wiwin Wiarsih ${ }^{3}$ \\ 1. Akademi Keperawatan Dr. Soedono Madiun, Jawa Timur 63117, Indonesia \\ 2. Program Studi Magister Fakultas Ilmu Keperawatan Universitas Indonesia, Depok 16424, Indonesia \\ 3. Fakultas Ilmu Keperawatan Universitas Indonesia, Depok 16424, Indonesia \\ *Email: muhidin_71@yahoo.com
}

\begin{abstract}
Abstrak
Mutu pelayanan keperawatan merupakan hasil dari harapan ideal yang dipersepsikan pasien dengan kenyataan yang diterima. Penelitian ini bertujuan mendeskripsikan persepsi pasien terhadap pelayanan keperawatan di RS X Madiun. Desain penelitian adalah fenomenologi deskriptif menurut Spiegelberg dengan teknik pengambilan sampel convenience sampling sejumlah 7 informan. Pengumpulan data menggunakan teknik in depth-interview dengan bentuk pertanyaan terbuka semi terstruktur. Hasil wawancara direkam dengan alat perekam kemudian ditranskrip verbatim dan dianalisis menggunakan metode Colaizzi. Penelitian menghasilkan 18 tema tentang persepsi pasien terhadap pelayanan keperawatan: alasan utama memilih rawat inap; alasan penunjang memilih rawat inap; puas pada pelayanan keperawatan; kecewa pada pelayanan keperawatan; toleran pada pelayanan keperawatan; sikap dalam merawat; atribut perawat; kemampuan kognitif; kemampuan teknikal; pengelolaan tugas; pemenuhan gizi; pemeliharaan lingkungan; pelaksanaan program terapi; aktivitas perawatan; perilaku perawat; penataan SDM keperawatan; pengembangan layanan keperawatan dan pengembangan strategis. Penelitian ini menyimpulkan bahwa pelayanan keperawatan yang dilaksanakan di RS X Madiun belum memenuhi harapan pasien, penerapan prinsip caring oleh perawat belum optimal, disebabkan oleh terbatasnya perawat baik secara kuantitas maupun kualitas. Pemerintah kota Madiun sebagai pengambil kebijakan disarankan untuk membenahi SDM keperawatan dengan cara menambah jumlah perawat, seleksi tenaga perawat yang kompeten, evaluasi kinerja, pendidikan dan latihan, dan supervisi keperawatan.
\end{abstract}

Kata kunci: fenomenologi, pasien, pelayanan keperawatan, persepsi

\begin{abstract}
Nursing service quality is results of an ideal hope which could create the patient perception based on received reality. The objecitives of this study was to explore the patient perception related to nursing services at RSUD Sogaten in Madiun District. This study used a descriptive phenomenology according to Spiegelberg by convenience sampling technique from 7 informants. Collecting data used in-depth interview technique in form of open-ended question by structural. Interview result recorded by tape recorder, and then it was transcripted by verbatim and it was analyzed by Colaizzi method. Study yield 18 themes concerning patient perception to nursing service: main reason to choose inpatient; reason of supporter choose taking care of to lodge; satisfied at service of treatment; satisfaction of nursing service; lenient of nursing service; attitude of nursing; nurse attribute; cognitive ability; technical ability; job management; nutrition accomplishment; environment maintenance; execution of therapy program; nursing activity; nurse behavior; settlement of nursing human resources; nursing service and strategic development. This conclusions of this study is nursing services at RSX Madiun did not fulfill patient hope yet, applying of caring principle by nurse is not optimal yet, because of limited of nurses both amounts and qualities. Government in Madiun District as policy maker was suggested to correct nursing human resources by the way of adding amount of nurse, select a competence nurse, performance evaluation, education, practice and nursing supervise.
\end{abstract}

Keywords: phenomenology, patient, nursing service, perception

\section{Pendahuluan}

Pelayanan keperawatan di rumah sakit merupakan salah satu pelayanan utama yang memiliki daya ungkit terbesar terhadap mutu pelayanan dan citra rumah sakit. Perawat memiliki interaksi yang paling luas dengan pasien, karena keterlibatannya pada hampir seluruh aktivitas pelayanan di rumah sakit. Kontak kekariban dalam aktivitas perawatan adalah elemen utama keunikan pelayanan keperawatan yang senantiasa dipersepsikan dan menjadi pengalaman berharga bagi pasien yang akan menentukan kualitas (Kirby \& Slevin, 1992). Penampilan perawat sebagai personil penentu kualitas pelayanan kesehatan baik di negara maju maupun negara berkembang masih belum mampu memenuhi tuntutan harapan dari pelanggan. 
Survei terhadap pelayanan keperawatan di rumah sakit di Kanada, Jerman, Skotlandia, Inggris, dan Amerika Serikat menemukan sekitar $17-44 \%$ perawat melakukan pelayanan keperawatan dengan kualitas memburuk dalam setahun terakhir (McLoughlin \& Leatherman, 2003). Penelitian Suryawati, Dharminto, dan Shaluhiyah(2006) menggambarkan ketidakpuasan yang dipersepsikan pasien di rumah sakit berhubungan dengan tutur kata, keacuhan, ketidakramahan, dan kesulitan memperoleh informasi dari perawat menduduki peringkat pertama.

Mutu pelayanan keperawatan, khususnya di rumah sakit umum pemerintah, belum memenuhi harapan pasien karena kurangnya tenaga keperawatan. Akibatnya rasio antara pasien dan perawat kurang memadai sehingga pekerjaan perawat melebihi kapasitasnya (Angsar, 2001 dalam Sudarma, 2008). Hal yang sama terjadi di RS X Madiun belum menunjukkan kinerja rawat inap yang optimal.

Pencapaian BOR berada di bawah standar Depkes (2003) yaitu $60-80 \%$ dalam 3 tahun masa berdirinya: tahun 2004, 11.39\%; tahun 2005, 14.91\%; dan tahun $2006,47.13 \%$. Kenaikan yang sangat signifikan pada 2007 yaitu sebesar $74.15 \%$ tidak diimbangi kebijakan penambahan tenaga oleh pemerintah kota Madiun. Akibatnya beban kerja perawat meningkat dan orientasi keperawatan lebih menekankan pada kegiatan yang bersifat pengobatan dibandingkan dengan kegiatan perawatan sebagai tugas pokoknya. Rumah sakit ini juga belum pernah melakukan evaluasi terhadap pelayanan keperawatan baik dengan pendekatan kuantitatifmaupun kualitatif. Upaya untuk menilai kualitas pelayanan keperawatan secara kualitatif dapat dilakukan dengan menilai persepsi pasien terhadap pelayanan dengan wawancara mendalam atau focus group discussion.

\section{Metode}

Metodologi riset yang digunakan adalah fenomenologi deskriptif. Pendekatan ini memungkinkan peneliti melakukan eksplorasi secara mendalam tentang persepsi pasien terhadap pelayanan keperawatan di RS X Madiun. Fenomenologi deskriptif merupakan cara mengeksplorasi dan mendeskripsikan suatu fenomena, dengan seoptimal mungkin membebaskan diri daripenilaian awal (Streubert \& Carpenter, 1999). Metode ini memiliki tiga tahap yaitu intusi, menganalisis, dan mendeskripsikan.

Tahap intuiting, menuntut peneliti memasuki secara total fenomena yang diteliti sehingga peneliti memahami secara mendalam fenomena sesuai deskripsi informan, tanpa kritik, atau melakukan penilaian serta memberikan pendapat terhadap fenomena tersebut. Data yang terkumpul melalui wawancara ditranskripsi dan dibaca berulang-ulang agar peneliti dapat mengkaji persepsi informan. Tahap analyzing dilakukan melalui identifikasi inti fenomena, memberikan kode terhadap informasi yang didapat, melakukan kategorisasi, menyatukannya ke dalam tema-tema dan melakukan analisis tema. Selanjutnya, tahap describing, dilakukan dengan membuat deskripsinaratif tentang tema-tema.

Penelitian ini dilakukan di ruang dewasa RS X Madiun. Penentuan informan dilakukan menggunakan teknik purposive sampling jenis convenience sampling. Kriteria informan meliputi pasien dewasa yang bersedia mengikutipenelitian, dalam kondisi stabil, minimal telah dirawat selama tiga hari, diutamakan yang telah memiliki pengalaman rawat inap sebelumnya dirumah sakit ini dan yang akan pulang. Kriteria tersebut dimaksudkan agar pasien mampu melakukan proses persepsi yang akurat dan telah memiliki intensitas yang cukup terhadap objek persepsi yaitu pelayanan keperawatan.

Kegiatan pengumpulan data dilakukan selama empat minggu dan mendapatkan tujuh informan (lima lakilaki, dua perempuan). Menurut Polit dan Hugler (2001) jumlah partisipan sebanyak ini mencukupi untuk mendapatkan saturasi data.

Pengumpulan data menggunakan teknik in-depth interview dengan bentuk pertanyaan terbuka semi terstruktur. Hasil wawancara disimpan dalam bentuk rekaman, kemudian ditranskrip verbatim dan dianalisis menggunakan metode Colaizzi. Etika penelitian diperhatikan dengan menggunakan prinsip otonomi, kerahasiaan, serta perlindungan dari ketidaknyamanan. 
Keabsahan data dijamin memenuhi prinsip kredibilitas, transferabilitas, dan ketergantungan.

\section{Hasil}

Karakteristik informan yang terlibat dalam penelitian ini adalah sebagai berikut: jumlah informan 7 orang ( 5 laki-laki dan 2 perempuan), usia berkisar antara 1960 tahun, berasal dari suku Jawa 5 orang, Nias 1 orang, dan Palembang 1 orang. Latar belakang pendidikan informan meliputi lulus SD 1 orang, SLTA 4 orang, dan 2 orang masih berstatus mahasiswa.

Lama hari rawat berkisar antara 4-7 hari, 4 informan pernah dirawat sebelumnya dan 3 orang baru pertama dirawat. Lama hari rawat berkisar antara 3-7 hari dengan diagnosis medis utama sebagai berikut: DM 4 orang, DBD 1 orang, efusi pleura 1 orang, dan batu empedu 1 orang.

Sebanyak 18 tema dihasilkan melalui content analysis tentang persepsi pasien terhadap pelayanan keperawatan di RS X Madiun, yang ditampilkan dalam P1-P7 yang memiliki arti Partisipan ke-1 sampai ke7. Penyajian tema dilakuan berdasarkan tujuan khusus penelitian dengan menampilkan contoh transkrip wawancara dengan informan.

\section{Alasan Pasien Memilih RS X Madiun sebagai Tempat Rawat Inap}

Dua tema meliputi alasan utama dan alasan penunjang memilih tempat rawat inap. Tema tersebut menggambarkan pemanfaatan rumah sakit yang masih terbatas pada masyarakat di sekitar rumah sakit, yang dilihat dari sosial ekonomi menengah ke bawah, serta derajat penyakit yang ringan saja.

"Alasan saya memilih disini itu ya tempatnya sederhana, maksudnya sederhana itu masalah biaya khan agak ringan" (P7).

“...karena deket dengan tempat tinggal saya disitu jalan...dan juga deket dari tempat dines saya...” (P2).

"Sebenarnya saya belum memilih rumah sakit ini...saya minta kamar kelas I di RS A nggak ada...terus mencari ke Merpati ( ruang VIP RSU A) itu juga penuh" (P1). “...kalau hanya demam-demam biasa saya lebih suka disini...tetapi kalau penyakitnya sudah menyangkut nyawa (mengacungkan jari telunjuk ke atas) saya akan pertimbangkan memilih rumah sakit lain”. (P5)

\section{Respon Pasien Terhadap Pelayanan Keperawatan}

Respon pasien terhadap pelayanan di rumah sakit bervariasi yaitu, puas, kecewa, dan toleran. Adapun faktor-faktor yang mendasarirespon tersebut meliputi sikap, ketrampilan, kemampuan komunikasi, dan keterbatasan dari rumah sakit.

“.... saya suka, puas.. karena mereka masih muda itu sopan, selalu permisi, ketuk pintu ketika masuk kamar..dan permisi setiap melakukan apa-apa" (P1).

“...ini lihat (menunjukkan punggung tangan dan kedua lipat sikunnya) biru semua khan...ini karena ulah perawatnya yang nggak terampil.....gitu kok bisa jadi perawatya?" (P4).

“...perawat yang kontrak itu gajinya cuma $R p$... sebulan ...lho kok terus kita suruh melayani seperti diswasta ya terang saja nggak bisa... kalau pelayannya masih beginibegini ya kita terima saja” (P3).

\section{Persepsi Pasien Terhadap Pelayanan Keperawatan}

Tema-tema yang tergali adalah sikap perawat bervariasi (baik dan tidak baik) meliputi aspek komunikasi, ketulusan, kesungguhan dan kepedulian. Sedangkan yang sudah baik adalah sikap adil dan menghibur.

Sikap dalam komunikasi yang tidak efektif seperti ditunjukkan dalam pernyataan berikut:

\footnotetext{
"Jadi saya lagi ngomong-ngomong rekan-nya masuk sêêt (menggerakkan telapak tangan pada posisi miring) pembicaran saya diputus (mengacungkan telunjuk) terus dia ngomong dengan temanya...ini khan sikap yang nggak baik.." (P1).
}

Sikap kurang tulus dalam bekerja:

“....masnya (perawat: red) itu kok nggak bersih (merawat luka: red) ....terlihat agak jijik dan asal-asalan gitu lo mas... sakit hati saya, kelihatan khan dari wajahnya dia itu jijik...”(P2). 
Sikap kurang peduli dariperawat:

“...kalau nggak lapor mereka nggak datang..ya datang sih datang tapi cuman kegiatan rutinya tensi, ngasih obat...kalau nggak ditanya nggak ngomong.... sprei ini kotor kalau nggak minta diganti ya tidak diganti" (P4).

Sikap yang adil dari perawat:

“...perawatnya disini itu ya tidak membeda-bedakan ini yang askes, ini yang bayar sendiri...” (P7).

Sikap menghibur :

"masnya itu yang gemuk waktu kontrol itu ya saya ajak bercanda ya biasa, bisa mengimbangi (tertawa dengan suara serak). Itu yang menyebabkan kerasan dan senang” (P7).

Makna kedua berhubungan dengan atribut perawat yaitu cara berpakaian yang tidak sesuai, dan dandanan yang sudah baik.

“... kadang ada yang memakai sandal jepit, padahal bajunya putih-putih dan dimasuk-kan rapi tapi kok pakai sandal jepit.. (tersenyum)" (P2).

“....nggak dandan berlebihan atau pakai perhiasan berlebihan kemrompyong (gemercing suara perhiasan: Jawa)" (P6).

Makna ketiga kemampuan kognitif dan teknikal juga bervariasi. Kemampuan kognitif yang baik.

“....semua dijawab dengan jelas oleh perawat, kemarin itu khan begini 2 hari itu saya melihat nasi saja kok sudah mual-mual to mas... kalau bapak mual coba pakek diabetasol...biar daya tahan tubuhnya kuat.... ternyata sarannya itu kok ya masuk akal..kenyataannya kondisi saya membaik setelah diberi itu” (P2).

Kemampuan teknikal yang kurang baik:

"Ngambil darah saja ndak bisa...dah dicoblos nggak ketemu. ya udah nggak apa-apa..saya bilang begitu..tapi dalam hati saya bilang kok bisa ya?" (P4).

Makna keempat berhubungan dengan manajemen pelayanan keperawatan yang belum optimal (pengelolaan tugas, pemeliharaan lingkungan, pemenuhan gizi, dan pelaksanaan program terapi). “...yang bagian obat ya cuma ngasih suntikan doang udah terus keluar atau kalau ada dokternya visite itu diem aja...nggak ngasih laporan gimana pasiennya gitu...(tertawa)...ya jadinya dokternya harus nanyananya lagi” (P4).

“.... kebersihan itu.. (menunjuk ke kanan dan ke kiri serta kamar mandi) ini (menarik sprei), pasien sebelah tadi yang pulang 25 hari itu tidak diganti sama sekali... saya disini selama 3 hari sprei juga belum diganti” (P6).

“...yang berurusan dengan soal medis itu sudah cukup memadai misal, obat yang diberikan dokter itu diberikan perawatnya semuanya dengan cukup bagus" (P3).

\section{Harapan terhadap Pelayanan Keperawatan}

Beberapa harapan pasien terhadap pelayanan keperawatan meliputi, 1) aktivitas perawatan yang jelas, 2) perilaku perawat yang baik, 3) pengelolaan SDM keperawatan, 4) pengembangan pelayanan, dan 5) Penyusunan rencana strategis.

Harapan pertama adalah aktivitas perawatan yang jelas, berupa adanya jadwal kerja dalam perawatan:

“...jadi pasien jam berapa harus dikontrol atau ini bagiannya siapa yang harus melihat pasien, dan kalau malem itu ruangan jangan ditinggal jadi harus ada suster jaganya” (P5).

Harapan kedua pada perbaikan perilaku perawat dalam memberikan pelayanan pasien mencakup sikap, keterampilan, dan kemampuan kognitif.

“...dia harus berperilaku ramah, ada diterap-kan berapa S gitu senyum, sopan, santun, sapa ..nah itu bagus itu...jadi sebelum diobati itu sudah tersentuh..." (P1).

"Agak serius gitu..kalau kerja ke pasien itu tidak mainmain.... mestinya cari dulu yang bener jangan langsung coblos.. "(P4).

Harapan pasien ketiga adanya penataan SDM keperawatan melalui penambahan tenaga, proses seleksi, evaluasi kompetensi, pendidikan dan pelatihan serta supervisi keperawatan.

“... kalau perawatnya cukup tentu lebih banyak waktu melakukan hal-hal kecil seperti ngecek tensi atau lihat infus yang habis itu akan lebih terjamin..makanya ya kalau bisa ditambah perawatnya" (P6). 
“...ketika masuknya mereka (perawat) dites saja..yang sudah bekerja juga bisa, jangan-jangan mereka benerbener nggak bisa gitu. Kalau emang jelek ya diikutkan pela-tihan...dan mestinya disini ada yang mengecek perawatnya bisa nggak bekerja. Bagaimana melayani pasien, sering dibenci pasien nggak?” (P4).

Harapan keempat adalah pengembangan pelayanan berupa penambahan ruangan, perbaikan layanan, kualifikasi layanan dan tarif.

Penambahan ruangan dan kualifikasi tarif seperti diungkap informan berikut.

\begin{abstract}
"Saya melihat kenapa ruangan ini kosong? Orang melihat kelas ini saja Rp.250.000,- dan yang itu Rp.50.000,-(menunjuk arah selatan), tapi kalau ada yang Rp.100.000,- khan ada alternatiflain. Jadi umpama VIP Rp.250.000,- kelas I Rp.100.000,- dan kelas I yang sekarang ini jadikan saja kelas II tarifnya Rp.50.000,dan kelas I dibuat yang baru saja dengan tarif Rp.100.000,-...”(P1).
\end{abstract}

Upaya perbaikan dapat dilakukan dengan melihat rumah sakit yang lebih baik.

“...lihat rumah sakit lain yang memang perawatperawatnya dan pelayanannya sudah baik gitu apa istilahnya..(menggaruk-garuk dahi) ...ya studi banding. Jadi studi banding ke RS lain misal RS B yang di Madiun itu kesannya sudah baik" (P6).

Harapan terakhir adalah penyusunan rencana strategis agar rumah sakit mampu bersaing dan diminati oleh masyarakat seperti terungkap berikut ini.

“...saya telah belajar bagaimana kemauan konsumen (partisipan adalah mantan Direktur Pemasaran Perusahaan Pupuk Nasional), kalau kita nggak tanggap ya kita akan dijauhi konsumen, pesaing kita banyak, setahu saya sudah mulai banyak rumah sakit di Madiun ini, sini, $R S A, R S B, R S C, R S D$ ada lagi itu yang masih membangun di sana (menunjuk ke arah selatan)..deket pabrik gula itu ...ya 6.. ”(P1).

\section{Pembahasan}

Pemilihan tempat rawat inap menurut Rosenstoch (1974) dan Becker dan Mainman (1975) dalam Potter dan Perry (1997) dipengaruhi oleh, 1) persepsi individu tentang kerentanannya terhadap suatu penyakit, 2) persepsi individu tentang keseriusan penyakit yang diderita (derajat keparahan), dan 3) persepsi terhadap manfaat yang akan diperoleh dari fasilitas layanan kesehatan yang diperoleh. Hasil penelitian ini sejalan dengan pendapat tersebut kecuali pada aspek kerentanan individu terhadap penyakit. Penelitian Riyarto dan Suprihanto (1999) memiliki kesamaan dengan penelitian ini yaitu faktor keterjangkauan harga (affordable) dan keterjangkuan jarak (accessible) pada kelompok masyarakat sosial ekonomi menengah ke bawah merupakan alasan utama dalam memilih tempat rawat inap.

Menurut Flaherty (1979) dalam DeWit (2005) pelayanan keperawatan memiliki sifat hakiki berupa: humanistic caring, nurturing, comforting, dan supporting dan karakteristik profesionalisme mencakup pendidikan, kode etik, penguasaan ketrampilan/ keahlian (mastery of a craft), keanggotaan dalam organisasi profesi dan akuntabilitas tindakan (accountability for action). Sifat hakiki dari pelayanan keperawatan harus dimiliki oleh setiap perawat dalam menjamin pelayanan yang memuaskan pasien. Hasil penelitian ini menunjukkan bahwa perawat yang memenuhi sifat tersebut mampu memberikan kepuasan pelayanan pada pasien, sebaliknya hilangnya salah satu sifat hakiki tersebut menyebabkan rasa tidak puas informan.

Dalam perspektif informan sifat humanistic caring dalam keperawatan dalam penelitian ini lebih utama dibandingkan aspek lain. Kondisi ini sejalan dengan pendapat Jacobalis (1995) sikap, perilaku, tutur kata perawat akan membentuk citra dalam diri pasien dan keluarganya. Tidak jarang walaupun pasien/keluarga merasa hasil perawatan (outcome) tidak sesuai dengan harapannya mereka tetap merasa cukup puas karena dilayani dengan sikap yang menghargai perasaan dan martabatnya.

Pelayanan rawat inap paling banyak melibatkan perawat dalam interaksinya dengan pasien dalam hubungan yang sensitif yang menyangkut kepuasan, mutu layanan keperawatan dan citra rumah sakit (Goodler, 1996). Perawat akan menjadi objek persepsi utama dalam setiap tingkah lakunya melayani pasien selama masa rawat inap. 
Persepsi pasien terhadap pelayanan keperawatan dalam penelitian ini menggambarkan bahwa perawat 1) belum mampu berperilaku caring secara totalitas dalam memberikan asuhan keperawatan, 2) belum memiliki kompetensi (kognitif, teknikal) yang memadai, 3) berpenampilan secara baik (penggunaan uniform), dan 4) mengelola pelayanan keperawatan secara baik (pemeliharaan ingkungan, pemenuhan gizi, pelaksanaan program terapi).

Tema-tema tentang persepsi pasien terhadap pelayanan tersebut sangat berbeda dengan hasil penelitian dari Hudachek (2008) 7 tema tentang persepsi pelayanan keperawatan yaitu : 1) kepedulian "caring", 2) kasih sayang, 3) kerohanian, 4) harapan yang melampaui target masyarakat, 5) memberikan kenyamanan, 6) intervensi krisis dan 7) pelayanan tanpa jarak. Dibandingkan dengan penelitian Hudachek (2008), penelitian ini hanya memenuhi aspek kepedulian, kasih sayang dan memberikan kenyamanan saja.

Belum terwujudnya aspek caring dalam pelayanan keperawatan di RS X Madiun, mengacu pada pendapat Marquis dan Houston (2000) dimungkinkan oleh 1) Visi, misi dan tujuan rumah sakit belum dijabarkan secara lokal pada tingkat ruangan, 2) Struktur kerja lokal, mekanisme kerja (standarstandar) yang diberlakukan di ruangan belum memadai, 3) sumberdaya manusia keperawatan yang belum memadai secara kualitas maupun kuantitas, 4) metode penugasan/ pemberian asuhan dan landasan model pendekatan kepada klien yang ditetapkan, 5) belum tersedianya sumber/ fasilitas yang mendukung pencapaian kualitas pelayanan yang diberikan, dan 6) kesadaran dan motivasi dari seluruh tenaga keperawatan.

Harapan informan terhadap pelayanan keperawatan di RS X Madiun menggambarkan kondisi ideal yang harus dilakukan pihak manajemen pelayanan rumah sakit khususnya pelayanan keperawatan yang secara garis besar meliputi sistem pemberian asuhan keperawatan yang ideal, perilaku ideal perawat dalam pelayanan keperawatan, manajemen SDM keperawatan dan upaya yang harus dilakukan agar rumah sakit ini dikenal serta dimanfaatkan oleh masyarakat.

Penelitian ini sesuai temuan Ani, Werdati dan Utarini (2001) tentang harapan pasien terhadap pelayanan keperawatan oleh di RSU Dharma Yadnya Bali tematema harapan pasien yang teridentifikasi adalah kenyamanan pelayananan keperawatan, kemampuan berkoordinasi perawat dalam bekerja, daya tanggap perawat terhadap kebutuhan pasien, profesional dalam pelayanan dan sikap empati dalam melayani pasien.

\section{Kesimpulan}

Persepsi pasien terhadap pelayanan keperawatan menggambarkan; pemanfaatan RSUD Sogaten kota Madiun terbatas pada masyarakat disekitar rumah sakit. Respon pasien terhadap pelayanan keperawatan menunjukkan bahwa kinerja perawat belum optimal akibat kurang kompeten. Perawat belum mampu berperilaku caring dalam memberikan asuhan keperawatan, belum memiliki kompetensi (kognitif, teknikal) yang memadai, belum berpenampilan secara baik, dan manajemen pelayanan keperawatan belum optimal. Perawat dirumah sakit diharapkan tanggap terhadap kebutuhan pasien, terampil, pandai, serta menghargai klien, serta upaya-upaya yang harus dilakukan jajaran manajerial rumah sakit untuk memperbaiki pelayanan keperawatan(JF, ENN, DW).

\section{Referensi}

Ani, S.L, Werdati, S., \& Utarini, A. (2001). Harapan pasien terhadap pelayanan keperawatan; penelitian kualitatif di RSU Dharma Yadnya Denpasar Bali. Jurnal Manajemen Pelayanan Kesehatan, 4 (1), 13-18.

Depkes RI. (2003). Pusat data dan Informasi. Diperoleh dari http://www. yanmedik-depkes.or.id/ kegPel/default.htmhome.

DeWit, S.C. (2005). Fundamental concepts and skills for nursing (Volume 1). Philadelphia: W.B. Saunders.

Goodler. (1996). Quality in health care. Makalah padaKonggres PERSI ke VII tanggal 25 28November 1996, Jakarta. 
Hudachek., S.S. (2008) Dimension of caring: A qualitative analysis of nurse's stories, phenomenology. Journal of Nursing Education. 47 (3), 124-300.

Jacobalis S. (1995). Menjaga mutu pelayanan rumah sakit suatu pengantar. Jakarta: Citra Windu Satria.

Kirby, C., \& Slevin, O. (1992). A new curriculum for care, in Slevin, O., \& Buckenaham, M., Project (2000). The teachers speak. Eidenburgh: Campion Press.

Marquis \& Houston (2000) Leadership roles and management function in nursing: Theory \& application (3rd ed). Philadelphia: Lippincott Williams \& Wilkins.

Mc.Loughlin, V. \& Leatherman, S. (2003). Quality or financing; What drives design of the design health care system? qualitatif safety health care. Washington DC: National Academic Press.

Murti, B. (2003). Mengembangkan indikator kualitas pelayanan kesehatan. Jurnal Manajemen Pelayanan Kesehatan, 6 (2).

Polit, D.F., Beck, C.T., \& Hungler, B.P. (2001). Essential of nursing research: Methods, appraisal and utilization. St. Louis: Mosby Year Book Inc.
Potter, P.A., \& Perry, A.G. (1997). Fundamental of nursing: Concepts, process, and practice. St.Louis: Mosby Year Book. (diterjemahkan oleh Asih Y, dkk, diterbitkan Jakarta: Penerbit Buku Kedokteran EGC)

Riyarto, S. \& Suprihanto, J., (1999). Evaluasi implementasi strategi pemasaran di Rumah Sakit Islam Jakarta Pusat. Jurnal Manajemen Pelayanan Kesehatan, 2 (1), 31-41.

Streuebert, H.J., \& Carpenter, D.R., (1999). Qualitative research in nursing advancing humanistic imperative (2nd ed). Philadelphia: Lippincott.

Sudarma, M. (2008). Sosiologi untuk Kesehatan. Jakarta: Penerbit Salemba Medika.

Suryawati, C., Dharminto, \& Shaluhiyah, Z. (2006). Penyusunan indikator kepuasan pasien rawat inap rumah sakit di provinsi Jawa Tengah. Jurnal Manajemen Pelayanan Kesehatan, 9 (4), 177184.

Pikiran kita ibarat parasut, hanya berfungsi ketika terbuka.

\section{- Thomas Dewar -}

Standar terbaik untuk mengukur keberhasilan Anda dalam kehidupan adalah dengan menghitung jumlah orang yang telah Anda buat bahagia.

- Robert J.Lumsden - 